\title{
Report of Independent Consultants Reviewing Integrated Test Stands (ITS) Performance and Readiness of DARHT for Construction Start
}

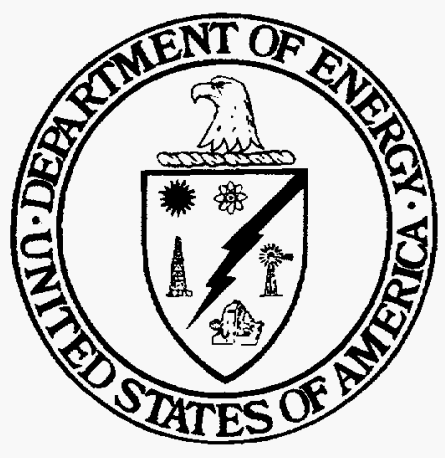

August 1993

U.S. Department of Energy Assistant Secretary for Defense Programs Office of Assistant Secretary for Military Application Washington, DC 20585 


\section{DISCLAIMER}

This report was prepared as an account of work sponsored by an agency of the United States Government. Neither the United States Government nor any agency thereof, nor any of their employees, make any warranty, express or implied, or assumes any legal liability or responsibility for the accuracy, completeness, or usefulness of any information, apparatus, product, or process disclosed, or represents that its use would not infringe privately owned rights. Reference herein to any specific commercial product, process, or service by trade name, trademark, manufacturer, or otherwise does not necessarily constitute or imply its endorsement, recommendation, or favoring by the United States Government or any agency thereof. The views and opinions of authors expressed herein do not necessarily state or reflect those of the United States Government or any agency thereof. 


\section{DISCLAIMER}

Portions of this document may be illegible in electronic image products. Images are produced from the best available original document. 
Report prepared by:

Jim Kapsales, Chairman

Henry A. Thiessen, Executive Secretary

Independent Consultants:

Richard K. Cooper

Andy Faltens

Terry F. Godlove

William B. Herrmannsfeldt

James W. Lyle

Craig L. Olson

Manuscript Prepared by Diane J. Wieting and Diane M. Boswell 
THIS REPORT CONTAINS THE OPINIONS OF INDEPENDENT EXPERTS CHARTERED BY THE DEPARTMENT OF ENERGY TO PROVIDE TECHNICAL INPUT TO THE DEPARTMENT REGARDING THE DARHT FACILITY. THE OPINIONS OF THESE CONSULTANTS DO NOT NECESSARILY REPRESENT DEPARTMENT VIEWS. 


\section{INDEX}

Page

1.0

Executive Summary

2.0

Introduction and Charge to Consultants

2.1 Introduction

2.2 Charge to Consultants

3

2.3 Agenda for Review

3.0

Consultant's Mutually Agreeable

Response to Questions

4.0

Independent Consultants' Responses to Questions

4.1 Dr. Richard K. Cooper

4.2 Mr. Andy Faltens

4.3 Dr. Terry Godlove

4.4 Dr. William Herrmannsfeldt

24

4.5

Mr. James W. Lyle

27

4.6 Dr. Craig L. Olson

5.0

Professional Profiles of Independent Consultants

Chairman

44

Executive Secretary

46

Appendix A

List of Acronyms

48

Appendix B

Charge from DOE

50

Distribution List

52 


\subsection{EXECUTIVE SUMMARY}

Independent consultants met at Los Alamos, June 15 and 16, 1993, to review progress on the commissioning of the Integrated Test Stand (ITS) for DARHT and to provide DOE with technical input on readiness for construction of the first radiographic arm of DARHT. The consultants concluded that all milestones necessary for demonstrating the performance of the DARHT accelerator have been met and that the project is ready for construction to resume. The experimental program using ITS should be continued to quantify the comparison of experiment and theory, to test improvements on the injector insulator, and to better evaluate the interaction of the beam and the target. 


\subsection{INTRODUCTION AND CHARGE TO CONSULTANTS}

\subsection{Introduction}

Hydrodynamic testing was developed at Los Alamos National Laboratory (LANL) as part of the Manhattan Project during World War II, and the facilities and techniques employed have evolved and continually improved. Many other nations have also developed hydrodynamic programs, including some which many observers consider to be more extensive than those of the United States. Hydrodynamics experiments represent the best data available for evaluation of primary performance except for that obtained during underground nuclear tests.

In the U.S., optical techniques, pins, and radiography are now commonly used at a variety of firing sites which can apply one or more technique to an individual experiment. The most capable facility at LANL for conducting hydrodynamic experiments is PHERMEX (Pulsed High Energy Radiographic Machine Emitting $X$-rays), which is over 30 years old. Experiments not requiring a full suite of diagnostics are performed at smaller firing sites at LANL.

The Dual-Axis Radiographic Hydrotest Facility (DARHT) program has been in the planning and development process for over 10 years, and has evolved considerably since it was first proposed. It was proposed by LANL in 1982 as a dual-axis pulsed diode facility following the example set by hydrodynamics programs outside the United States. The eventual success of the single-axis FXR (Flash X-Ray Machine) facility whose construction was completed in 1980 at Lawrence Livermore National Laboratory (LLNL) and an improved understanding of primary physics led LANL to subsequently upgrade the DARHT facility concept to a linear induction accelerator design in 1987. The 1988 DARHT design was intended to result in a facility whose accelerators could exceed the performance of FXR and provide the U.S. with the nation's only dual-axis capability, drawing on experience developed outside the United States. Construction of nonaccelerator portions of the facility commenced in 1989, and LANL conducted experiments at FXR which indicated that further improvements in linear induction accelerator technology were possible. In the 1990 s another country expressed interest in obtaining DARHT technology for a new facility similar to one axis of DARHT but with modifications to the injector, and initiated the required overtures to the U.S. to begin that process.

LANL convened a panel of internal and external experts in 1990 (referred to as the Leiss Panel) 1 which recommended several minor program management changes and a serial approach to construction, with an Integrated Test Stand (ITS) first established before a complete first axis was built. The ITS was defined as the injector for the first axis and the first eight of an eventual 48 voltage cells. Five performance milestones were established. Construction was limited by the

\footnotetext{
1 Report on the Design Review of the Dual Axis Radiographic Hydrodynamic Test (DARHT) Facility Linear Induction Accelerators, LANL internal report, June 1990.
} 
Department of Energy (DOE) in 1990 pending performance demonstration of the ITS.

DOE chartered two outside reviews by independent consultants in 1991. The DARHT Feasibility Assessment Independent Consultants (DFAIC) ${ }^{2}$ and the Hydrotest Program Assessment Independent Consultants (HPAIC) ${ }^{3}$ reports were completed in 1992. HPAIC confirmed the utility of the hydrodynamics information expected to be provided by the facility. LANL had completed the first 4 Milestones of the Accelerator Development Plan at the time the DFAIC review was completed. DFAIC recommended in addition to completing Milestone 5, an additional performance milestone called the Tickler experiment be conducted before resuming construction.

Subsequent to DOE evaluation of technical input provided by DFAIC and HPAIC to the DOE Deputy Assistant Secretary for Military Application, in 1992 the DOE Assistant Secretary for Defense Programs approved funding of full-scale construction of DARHT to resume in 1994 pending technical input contained in this report by the 1993 DARHT Accelerator Review. DOE directed LANL to modify the DARHT design by expanding the diagnostic area to accommodate advanced diagnostics being developed by LLNL, thereby allowing DARHT to serve as a user facility. DOE also mandated that LANL successfully complete construction and operation of the first axis accelerator before approving procurement of the second axis accelerator. DOE allowed the site preparation and building for both axes of the accelerator to be completed during the construction to allow uninterrupted use of the first axis and the firing site during eventual procurement of the second axis accelerator. Later in 1992 and continuing into 1993 unexpected and repeated failures of the radial insulator of the ITS injector occurred. Assessment of those failures was included in the charter for the 1993 DARHT Accelerator Review.

\subsection{Charge to Consultants}

The DARHT Accelerator Review was chartered by the U.S. Department of Energy (DOE), Deputy Assistant Secretary for Military Application, Defense Programs, to provide technical input by independent consultants to the Department concerning the proposed completion of the DARHT facility and the likelihood it would meet its performance specifications and operating requirements. The consultants were requested to review the milestones and the performance of the Integrated Test Stand. An integral part of the review included assessment of the injector insulator reliability, Milestone 5 of the Accelerator Development Plan, and the Tickler experiment recommended by DFAIC. The review addressed activities at LANL since the completion of the DFAIC and HPAIC reviews. The full text of the charter is reproduced in Appendix $B$.

2 DARHT Feasibility Assessment Independent Consultants DFAIC Panel, Sandia National Laboratories, Sandia Report SAND92-2060/UC-700, September 1992.

3 Hydrotest Program Assessment, Pacific-Sierra Research Corporation, PSR Report 2320, October 1992. 
The review was coordinated by Mr. Jim Kapsales, Weapons Physics Program Manager for the Department of Energy, and was accomplished by the following experts from private industry and research laboratories:

\section{Dr. Richard K. Cooper, Los Alamos National Laboratory/AT Division}

Mr. Andy Faltens, Lawrence Berkeley Laboratory (LBL)

Dr. Terry F. Godlove, FM Technologies, Inc.

Dr. William B. Herrmannsfeldt, Stanford Linear Accelerator Center (SLAC)

Mr. James W. Lyle, Lawrence Livermore National Laboratory Associate (Retired)

Dr. Craig L. Olson, Sandia National Laboratories (SNL)

Dr. Henry (Arch) Thiessen of Los Alamos National Laboratory/Medium Energy Physics Division served as Executive Secretary. Jim Kapsales of DOE acted as Chairman until the consultants met for the first time. At that time the consultants were requested to elect a Chairman. They requested that Mr. Kapsales continue to assume those duties. In order to ensure that the desired independence of the consultants weas maintained, Mr. Kapsales acted in an ex-officio capacity and provided the consultants with the opportunity to conduct portions of the executive sessions in private without the Chairman present. Neither the Chairman nor the Executive Secretary participated in the development of technical input or recomendations by the consultants. Section 5.0 contains the Professional Profiles of the Consultants, Chairman, and Executive Secretary.

The participating personnel from Los Alamos National Laboratory were selected from outside the Associate Directorate for Nuclear Weapons Technology, whose proposed facility was the subject of the review; Dr. Cooper previously participated on the Leiss Panel. The participating consultant from LLNL (Mr. Lyle, recently retired) has extensive experience with radiographic facilities at LLNL site 300, and has not participated in any previous review of DARHT. Drs. Godlove and Olson previously participated in the DFAIC review. Dr. Herrmannsfeldt participated in the DFAIC review and portions of the HPAIC review. Mr. Faltens has extensive accelerator experience at LBL and was not a participant in any previous review of DARHT. Mr. Kapsales previously acted as Coordinator of the DFAIC and HPAIC reviews.

The consultants met on June 15 and 16, 1993 at TA-15, LANL. An Introductory session was conducted on June 14, 1993 to acquaint consultants, not participating in any of the previous DARHT reviews (Jim Lyle and Andy Faltens), with the project. The consultants were briefed by members of the DARHT Project and an internationally recognized expert in linear induction accelerator technology from LLNL (Dr. George Caporaso) under contract to the DARHT project. They were also briefed by Dr. Cooper on the Leiss internal review chartered by LANL, by Dr. Godlove on the DFAIC assessment, and by Mr. Kapsales on the HPAIC assessment and subsequent DOE activities. Mr. Robert Hamby of the Office of the DOE Deputy Assistant Secretary for Facilities was requested to provide comments on the status of the construction project. Dr. Lloyd Multhauf of the LLNL was present as an observer. The agenda is included in this section. 
This report contains the technical input from the consultants reviewing the 1993 status of DARHT. It is anticipated that other reviews will be conducted periodically in the future as the project continues to develop. The consultants were requested to provide individual inputs to a series of questions submitted by the Chairman. No consensus was required or expected. Section 3.0 of this report contains input to those questions which were common to the positions taken by all of the consultants and to which all of the consultants have agreed. Each of the questions was assigned to one of the consultants for the lead role in writing a response representing whatever common technical inputs evolved from all consultants. Section 4.0 of this report contains individual and independent responses from each consultant in response to those questions. Section 2.0 of this report was written by the Chairman. The Executive Secretary drafted Section 1.0, and assembled and edited the report, with the exception of Section 4.0 the content of which is unedited. 


\subsection{Agenda for Review}

M-4 Conference Room (TA-15, BIdg. R40, Rm. 110)

15 June 1993

$\begin{array}{rll}\text { 8:30 } & \text { Executive Session } & \text { Kapsales } \\ \text { 8:55 } & \text { Welcome } & \text { Porter } \\ \text { 9:00 } & \text { Program Perspective } & \text { Burns } \\ \text { 9:30 } & \text { DOE/Consultants Presentation } & \begin{array}{l}\text { Cooper, } \\ \text { Godlove }\end{array} \\ \text { 10:00 } & \text { Break } & \\ \text { 10:15 } & \text { DOE/Consultants Presentations (Cont'd) } & \text { Kapsales } \\ \text { 11:00 } & \text { Program Review Synopsis } & \text { Burns } \\ \text { 11:45 } & \text { Working Lunch } & \text { All } \\ \text { 1:00 } & \text { ITS Tests and Results } & \text { Moir/Allison } \\ \text { 2:30 } & \text { Tickler Tests } & \text { Caporaso } \\ \text { 3:30 } & \text { Break } & \\ 3: 45 & \text { Performance Prediction } & \text { Allison } \\ \text { 4:15 } & \text { Executive Session } & \text { Kapsales } \\ 5: 00 & \text { Debriefing } & \text { Kapsales, et al } \\ 5: 15 & \text { End } & \end{array}$


16 June 1993

$\begin{array}{rll}\text { 8:30 } & \text { Injector Insulator and Cathode Shroud } & \text { Carlson } \\ \text { 10:00 } & \text { Break } & \\ \text { 10:15 } & \text { Induction Cell and Pulsed Power Status } & \text { Downing } \\ 10: 50 & \text { Target Interactions } & \text { Moir } \\ 11: 15 & \text { Tour ITS } & \\ 12: 15 & \text { Working Lunch } & \text { All } \\ 1: 00 & \text { Project Completion } & \text { Jolly } \\ 1: 30 & \text { Project Assessment } & \text { Burns } \\ 2: 30 & \text { Break } & \\ 2: 45 & \text { Executive Session } & \text { Kapsales } \\ 4: 45 & \text { Debriefing } & \text { Kapsales, et al } \\ 5: 00 & \text { End } & \end{array}$




\subsection{CONSULTANT'S MUTUALLY AGREEABLE RESPONSE TO QUESTIONS}

The following set of questions and answers represents the mutually common technical input of all the independent consultants. Individual elaborations by each independent consultant to each question are contained in Section 4.0. In some cases those elaborations contain some input not contained in this section.

1. Question: Are the stated ITS performance milestones adequate to predict the performance of DARHT?

Answer: Yes, but the real significance is that the results of the tests have shown the hoped-for improvements. It was quite possible that the problems that were identified in FXR (alignment errors leading to corkscrew, etc.), were not the only causes of the observed spot size. If the ITS tests had not worked as well as they did, it would have meant that other problems still remained to be diagnosed and cured. The good results give great confidence that the real problems have been faced and the cures work.

2. Question: is there enough information available to address ITS performance?

Answer: Yes. The ITS performance has been adequately demonstrated. Questions do exist relative to the ongoing beam-target interaction experiments, testing the upgraded power cells, and continuing R\&D on the injector insulator, but these questions do not detract at all from the basic demonstration of ITS performance.

3. Question: Is the performance of the injector (insulator) adequate?

Answer: Yes, the performance of the insulator is adequate to proceed with the building of DARHT and running the injector at a voltage of $3 \mathrm{MV}$. This recommendation is based on greater than 7,000 pulses successfully demonstrated at operational voltages higher than $3 \mathrm{MV}$, and the prospects of improved insulators and scheduled maintenance on the insulators. Moreover, it was believed that a successful radiograph would be made even on a pulse on which an insulator breaks, because the breakdown occurs later in time. However, we support continued improvements on the insulator and the injector voltage pulse train in order to reach a larger safety 
factor, specifically: to continue efforts to reduce the injector pulse ringing; to develop the better insulator materials; to continue investigations on insulator resistive grading; and to collaborate with others doing similar developments, especially Sandia, which has a great deal of experience on insulator breakdown.

4. Question: Is the proposed (by LANL) tradeoff among injector parameters to maintain radiographic performance expectation considered acceptable?

Answer: Yes, it is acceptable, but it is not entirely desirable. The tradeoff uses most of the headroom that existed in the original conservative design. LANL should continue to work on this problem, as indeed they plan to do, including cooperating with the French/PSI work. Ultimately it may be desirable to go to an injector design that trades off some of the pulsed high voltage for some induction core voltage, similar to the FXR approach.

5. Question: Are there any issues that should impact the FY'94 program procurement plan?

Answer: There is total agreement that procurement for one complete accelerator should proceed without delay. However, there is not complete agreement on the perpendicular footprint (concrete base plus utilities) for the second accelerator. The majority opinion is that the perpendicular footprint of the second accelerator should proceed without delay. The minority opinion 4 is that parallel accelerators and magnetic bends should be considered before committing to a perpendicular footprint.

6. Question: Has ITS milestone 5 been met or exceeded?

Answer: Yes. A dose greater than 18 Rad and a spot size smaller than $4.7 \mathrm{~mm}$ have been achieved.

7. Question: Has the tickler experiment been successfully completed and assessed?

Answer: Yes. An upper bound has been established for BBU growth that shows that BBU will not be a problem for the full accelerator. The theoretical analysis of George Caposaso and Tom Hughes, and the experimental work of Dave Moir, Paul Allison, and Mike Burns are to be

${ }^{4}$ See response to Question \#5 by Independent Consultant, Craig L. Olson, Section 4.6. 
commended. Work should continue to improve the agreement between code results and experiments. Other parameters should now be varied, such as the current, for thorough understanding of BBU.

8. Question: Has the beam/target interaction been adequately addressed?

Answer: Experiments with different target materials have demonstrated: a) The Integrated Test Stand (ITS) beam quality (stability and size) is good, as evidenced by the graphite target streak camera photographs. b) There is a potentially troublesome interaction with the target that needs further experimentation to resolve. c) This interaction gives the beam an appearance of filamentation, which needs further characterization. This interaction could scale with energy in an unknown way. Experiments at the Flash X-Ray (FXR) machine at Livermore might shed further light on the issue.

9. Question: Are the technical risks associated with DARHT acceptable?

Answer: Yes. The research and development undertaken at LANL in the past three years has advanced the state of the art in linear induction accelerator design. Given the successful operation of ETA, ATA, and FXR, it is reasonable to state that the DARHT machine will also be successful. The careful attention given to the details of construction and alignment, and the incorporation of correction coils, augur well for a successful turnon and operation of the facility.

10. Question: What is the probability that DARHT will meet its radiographic operating requirements?

Answer: The probability is high that DARHT will meet its radiographic operating requirements, but not necessarily when it is first turned on. The requirements of on-target electron current, energy, pulse width, and x-ray dose are highly likely to be met when the machine first becomes operational. The spot size of $1.2 \mathrm{~mm}$-diameter $4 \mathrm{rms}$ time-averaged over 60 ns is the more difficult goal to realize, but it is possible given our present understanding of the physics, the design of the machine, and the demonstrated performance of the Integrated Test Stand (ITS). The performance history of electron accelerators for flash radiography shows that the machines were considerably improved in a few years from the original start-up. Such improvement is expected to occur for DARHT as well. There are trade-offs available to optimize various radiographic tasks. For example, the spot size can be made smaller through the use of collimation at a sacrifice of some dose. Dose can be increased with higher 
electron energy which might require additional accelerating cavities for which the designers have already provided.

11. Question: Should the second axis differ significantly from the first?

Answer: This partly depends on continuing feedback from the users. The option should be left open as long as possible. We expect tests and improvements on the final focus and beam transport geometry, especially bends, which could affect the second axis design. We also expect a better injector to evolve with time. In general, the longer the time interval available for the technical progress, the greater would be the expected differences which should be incorporated into the second axis.

12. Question: Are there any recommendations for further (1) DOE Technical Reviews? (2) R\&D Plans for radiography applications?

Answer: Yes, regarding radiography applications; the user community at both nuclear design laboratories should be involved, with the accelerator and radiography scientists, to determine the most useful options. Possibilities include multiple views at different angles, with multiple pulses, or gated single pulses, to get a radiographic motion picture of a test. Such a study should be made before it is necessary to freeze the design for the second arm of DARHT.

13. Question: Are there other recommendations?

Answer: Yes, considering the possibility that underground testing will not be restarted, there is also a possibility that a much more urgent need will arise for access to DARHT. The project is on a very slow, funding limited, schedule. Therefore, LANL should develop a project plan for accelerating the schedule if the pace of funding is not constrained.

14. Question: What tests of the proposed 11 ferrite-ring cell should be accomplished before the full procurement action is taken?

Answer: Measure the actual pulse and verify the expected pulse length operation, then operate at $>300 \mathrm{Kv}$ to get assurance of high voltage holdoff in this new design. 
15. Question: Could the Livermore FXR be used to answer and other questions?

Answer: FXR could be used to answer questions that may be important both for the design of DARHT and for improvements of the FXR. For example: The interactions of the tightly focused electron beam and the bremsstrahlung target could be explored to improve our understanding of some very complex electronic and hydrodynamic phenomena that has recently been observed on the ITS. The FXR could be used in the postaccelerator drift region to develop a more nearly achromatic focusing system. A tickler-like experiment could be done on FXR in which microwave energy could be introduced while evidence of propagation of beam break-up modes is examined. 


\subsection{INDEPENDENT CONSULTANTS' RESPONSES TO QUESTIONS}

\subsection{Independent Consultant - Dr. Richard K. Cooper}

On June 15 and 16, I was one of six independent reviewers who heard a technical presentation by the DARHT team. Topics covered included the highvoltage injector, the linac accelerating cells, the tickler experiment, and beamtarget interactions. As a collection of reviewers we developed a set of questions that is relevant to the project and which will be addressed by each reviewer in his report on the project. I will address these questions below, but wish to make a statement up front in something like an executive summary.

The research and development carried out by the DARHT team has been first class. The team has availed themselves of all the calculational tools currently being used in the design community, and they have availed themselves of the expertise in other laboratories as needed. The DARHT design is a significant advance in the state of the art in induction linac design. Given the successful operation of previous induction linacs, there is every reason to believe that the DARHT linacs will be very successful, and that the DARHT facility will provide the laboratory and the nation with a valuable $x$-ray source with numerous applications to the imaging of explosively-driven systems. In my opinion, it is imperative that the construction of the facility be undertaken as soon as possible, before the talent which has been assembled drifts off into other, more immediate endeavors.

Below is the list of questions to be answered by each of the independent reviewers, followed by my answers.

1. Question: Are the stated ITS performance milestones adequate to predict the performance of DARHT?

Answer: Yes. Most difficulties in accelerators occur at the injector and the low-energy end of the accelerator. The ITS performance being acceptable is a strong argument for successful operation of the entire accelerator. The primary exception to the general statement about difficulties occurring at low energy is the cumulative beam breakup phenomenon, which depends strongly on the length of the accelerator. The DARHT team has addressed the beam breakup issue very carefully and with requisite skill, so that I am confident that the accelerator will work as designed.

2. Question: Is there enough information available to address ITS performance? 
Answer: One can always gain more data by running more and more shots, but present data is sufficient to project adequate performance.

3. Question: Is the performance of the injector (insulator) adequate?

Answer: Yes. The insulator failure recently encountered has been dealt with carefully, to the point that one can see that, in routine operation of the facility, at worst insulator failures becomes a maintenance operation. Lowering of the injector voltage by 20 to $30 \%$ will minimize the maintenance level while affecting overall performance only slightly. In any case, there is no danger of a hydro test being lost, as breakdowns occur only after the pulse is complete.

4. Question: Is the proposed (by LANL) tradeoff among injector parameters to maintain radiographic performance expectation considered acceptable?

Answer: Yes. See previous answer.

5. Question: Are there any issues that should impact the FY'94 program procurement plan?

Answer: No. In my opinion, the team is ready to go and the design is ready to go.

6. Question: Has ITS milestone 5 been met or exceeded?

Answer: Yes.

7. Question: Has the tickler experiment been successfully completed and assessed?

Answer: The comparison between theory and experiment appears good enough. This comparison might be easier to make, and the results less ambiguous, by using the measured beam offsets as input to the beam breakup codes, rather than assuming an offset. These offsets can be obtained as a function of time at the beam position monitor following the tickler.

8. Question: Has beam/target interaction been adequately addressed?

Answer: Experiments with different target materials have demonstrated:

a) The Integrated Test Stand (ITS) beam quality (stability and size) is good, as evidenced by the graphite target streak camera photographs. 
b) There is a potentially troublesome interaction with the target that needs further experimentation to resolve.

This interaction could scale with energy in an unknown way. Experiments at the Flash-X-Ray (FXR) machine at Livermore might shed further light on the issue.

9. Question: Are the technical risks associated with DARHT acceptable?

Answer: Yes. The research and development undertaken at LANL in the past three years has advanced the state of the art in linear induction accelerator design. Given the successful operation of ETA, ATA, and FXR, it is reasonable to state that the DARHT machine will also be successful. The careful attention given to the details of construction and alignment, and the incorporation of correction coils, augur well for a successful turnon and operation of the facility.

10. Question: What is the probability that DARHT will meet its radiographic operating requirements?

Answer: Greater than $95 \%$.

11. Question: Should the second axis differ significantly from the first?

Answer: If the decision had to be made today, the answer would be no. Not being able to predict the future with absolute certainty, I would say that when the time comes to make that decision we should examine the options in light of the current needs for the facility.

12. Question: Are there any recommendations for further (1) DOE Technical Reviews? (2) R\&D Plans for radiography applications?

Answer: (1) In my opinion, the next technical review should take place no sooner than halfway into the construction project. This review should be requested by the DARHT team when and if they feel they need it.

(2) I think the users of the facility should always be thinking of new and better ways to use the output of machines like PHERMEX, FXR, and DARHT. DOE should entertain proposals for such R\&D.

13. Question: Are there other recommendations?

Answer: Ways should be explored to speed up the project to allow experiments to be performed that would allow the US to extrapolate from 
NTS experience to DARHT experiments. It would be most desirable to have Nevada tests ongoing at the time DARHT is operational, so best to correlate the results of both kinds of testing.

14. Question: What tests of the proposed 11 ferrite-ring cell should be accomplished before the full procurement action is taken?

Answer: Such a cell should be fabricated and tested for voltage holding capability, for voltage waveform, and for transverse coupling impedance. Assuming these are all satisfactory, the ferrite core procurement should be undertaken.

15. Question: Could the Livermore FXR be used to answer any other questions?

Answer: Depending on availability of FXR time, it could be used to study the beam-target interaction as a function of energy, especially if the spot size on the target could be made small enough to reproduce the ITS results on tantalum. This study may well turn out to yield some basic physics phenomena. 
4.2 Independent Consultant - Mr. Andy Faltens

1. Question: Are the stated ITS performance milestones adequate to predict the performance of DARHT?

Answer: The stated ITS performance milestones are adequate to predict good performance from DARHT

2. Question: Is there enough information available to address ITS performance?

Answer: These milestones were adequately met.

3. Question: Is the performance of the injector (insulator) adequate?

Answer: The injector and especially its insulator were topics of concern and received a great deal of attention in the presentations and discussions. Clearly, the solution taken by LANL to reduce the operating voltage is the correct one and adequate life of the insulator has been demonstrated in that mode. The gun design should continue to look for lower-voltage acceptable solutions, because even the 3 MV point seems higher than necessary. Simultaneously, the insulator improvement effort of using better materials and better voltage grading should continue.

4. Question: Is the proposed (by LANL) tradeoff among injector parameters to maintain radiographic performance expectation considered acceptable?

Answer: The proposed injector tradeoffs and improvements should continue. The induction linac basically is used because it replaces a very large single voltage with respect to ground with many small inductive voltage increments. It would be false economy to compromise the operation of the facility by using a high voltage "pulse power" diode because it is cheaper than an inductive gun drive. The desirable direction to go in is to use as much inductive drive as possible for the gun, even though it costs more (as was done on ASTRON, ERA, ETA, ATA, FXR) because this reduces the total (and excess) energy in the system and greatly reduces the probable damage from a breakdown. An intermediate solution might be to reduce the voltage a little in the transmission line transformer by better terminations of the pulse, and thereby reduce the pulse ringing, and to make up the voltage reduction by an additional inductive unit so as to maintain constant gun voltage. 
5. Question: Are there any issues that should impact the FY'94 program procurement plan?

Answer: There are no outstanding issues that should delay the start of major procurements. There was discussion of possible improvements, which, in my opinion should not be causes for delay; but rather, for system improvements now if time allows, or later in an upgrade program.

6. Question: Has ITS milestone 5 been met or exceeded?

Answer: Yes, the required dose and spot size were met.

7. Question: Has the tickler experiment been successfully completed and assessed?

Answer: A very nice job was done on the tickler and the results show that the coherent transverse oscillation growth in DARHT will not be a serious problem. As added insurance the few small metallic enlargements in the vacuum chamber, for beam pickup loops and bellows, should be measured, the effects of their resonances - which are near the pipe cutoff - calculated, and if necessary detuned and damped.

8. Question: Has beam/target interaction been adequately addressed?

Answer: There is obviously something occurring in the last few feet of the final transport and focusing system that is affecting the beam. Some of the suggested possible causes, such as backstreaming, photodesorption, filamentation, etc., have clear, corrective actions. It is too soon to tell whether the phenomenon is very damaging. Consequently, this remaining mystery should continue to be investigated, again with perhaps some consultation with other laboratories.

9. Question: Are the technical risks associated with DARHT acceptable?

Answer: Yes. There is substantial corroborative experience from other machines, and the most serious technical questions have been addressed on the ITS.

10. Question: What is the probability that DARHT will meet its radiographic operating requirements?

Answer: The major issues for the successful operation of DARHT have been addressed and there is a high probability that the machine and the radiography will be successful. 
11. Question: Should the second axis differ significantly from the first?

Answer: This partly depends on continuing feedback from the users. The option should be left open. Expect tests and improvements on the final focus and beam transport geometry especially bends, expect better injector evolution, with time, expect greater changes.

12. Question: Are there any recommendations for further (1) DOE Technical Reviews? (2) R\&D Plans for radiography applications?

Answer: Yes, see the group responses to Questions 11 and 12.

13. Question: Are there other recommendations?

Answer: There are two kinds of beam bending which should improve the DARHT facility. The first is simply to treat the beam as any common beam and move it around as required to suit experimental requirements rather than to be boxed in by the present accelerator configuration. The second bending option is to provide just some very slight bends which would prevent target debris from flying all the way back and damaging the cathode. Some study is warranted to see if the beam emittance suffers because of such bends; this could be a theoretical study or an experiment. The risks associated with a slight bend seem very small.

14. Question: What tests of the proposed 11 ferrite-ring cell should be accomplished before the full procurement action is taken?

Answer: Measure the actual pulse and verify the expected pulse length operation, then operate at $>300 \mathrm{kV}$ to get assurance of high voltage holdoff in this new design.

15. Question: Could the Livermore FXR be used to answer any other questions?

Answer: Yes, see the group response and Jim Lyle's response. 


\subsection{Independent Consultant - Dr. Terry F. Godlove}

1. Question: Are the stated ITS performance milestones adequate to predict the performance of DARHT?

Answer: Yes. The ITS "tickler" experiments were judged to be an issue a year ago. The LANL team, with help from LLNL, has collected enough beam breakup (BBU) data, and compared the data with theory, to convince me that BBU is small enough for the full machine to operate within specifications.

2. Question: Is there enough information available to address ITS performance?

Answer: Yes. The ITS performance has been adequately demonstrated. Questions do exist relative to the ongoing beam-target interaction experiments, testing the upgraded power cells, and continuing R\&D on the injector insulator, but these questions do not detract at all from the basic demonstration of ITS performance.

3. Question: Is the performance of the injector (insulator) adequate?

Answer: Yes, in terms of the ITS performance and projected DARHT performance. However, it would be prudent to have more breathing room. The R\&D initiated after the insulator failures, combined with the French/PSI project, convince me that the insulator, with high probability, is adequate and will be improved in time.

4. Question: Is the proposed (by LANL) tradeoff among injector parameters to maintain radiographic performance expectation considered acceptable?

Answer: Yes, in terms of the projected DARHT performance. However, as noted in (3), the continuing R\&D program on the insulator is important to improve reliability and provide breathing room.

5. Question: Are there any issues that should impact the FY'94 program procurement plan?

Answer There are no issues that should effect the FY'94 program procurement plan.

6. Question: Has ITS milestone 5 been met or exceeded? 
Answer: Yes. The beam spot size and dose requirements have been exceeded.

7. Question: Has the tickler experiment been successfully completed and assessed?

Answer: Yes. The LANL team, with particular help from George Caporaso of LLNL, obviously worked hard to obtain these difficult measurements. We were presented with four sets of measurements and theory predictions, including both transverse planes and two magnetic field configurations (a low-field case and a high-field case). In addition, calculations were carried out with nominal cavity parameters and with "maximum tolerable" cavity parameters. While the agreement is by no means perfect, it is adequate to convince me that the BBU will be small and tolerable. There are small uncertainties in the calculations and the beam measurements are hard when the BBU gain is small. Also, the cavity parameters cannot be measured with great precision. (This is in part why we were concerned a year ago). Nevertheless, the team made a convincing case that the BBU growth is satisfactorily bounded.

8. Question: Has beam/target interaction been adequately addressed?

Answer: Yes and no. Yes, from the standpoint of continuing construction; no, in the context of ongoing research to fully characterize the interaction. The review included description of experiments which showed a small beam instability when striking tantalum, but not graphite. These observations need more research to identify the cause. My on-the-spot speculation was that it might involve intense $x$-rays from the target hot spot. The dense plasma temperature might be very high. In any case, some calculations by the right person(s) and some more measurements seem in order. The purpose would be to make sure that the interaction does not impact the DARHT performance.

9. Question: Are the technical risks associated with DARHT acceptable?

Answer: Yes, in my opinion. Several of the items addressed in these questions, e.g., the insulator and the target interaction, involve small but acceptable risk in the context of ongoing R\&D and in the context of a normal shakedown period.

10. Question: What is the probability that DARHT will meet its radiographic operating requirements? 
Answer: Very high, in my opinion, in the same sense as the answer to Question 9.

11. Question: Should the second axis differ significantly from the first?

Answer: Maybe. In view of the agreed-upon delay of the second axis. I would rather delay the answer to this question. One issue is multiple pulsing; another is a whole new improved injector with perhaps higher current and/or higher reliability; another is beam deflection magnets; finally, experience operating the first axis may indicate change.

12. Question: Are there any recommendations for further (1) DOE Technical Reviews? (2) R\&D Plans for radiography applications?

Answer: I got the distinct impression that little or no thought has been given to the possibility that beam deflection magnets might be desirable between the linac(s) and the firing table. Several compact achromatic deflection and/or beam translation methods are available. Such systems might provide a lot of flexibility in the geometry of the firing table. What geometries might the users be interested in which were thrown out because they were considered impossible or too awkward? Also, a deflection system would eliminate the unwanted beam during the rise and fall time of the pulse, making the target design easier. This question would evidently require some study and review. Regarding the linac per se, the technical issues are raised in other questions herein. In my opinion, the linac issues are not serious enough to warrant review for at least a year and certainly not serious enough to delay construction.

13. Question: Are there other recommendations?

Answer: I think the LANL team, and George Caporaso, should be highly commended for the work they have done, especially in recent months. The BBU growth now appears to be small. While the insulator failures were a blow, the sum total of the improvements plus the French/PSI effort should alleviate that situation. During the previous review, I was greatly impressed with the design of the focusing magnets, and they have now been proven. Many other aspects of the design, e.g., diagnostics, low-impedance cell design, etc., are first class. I think DARHT is going to be the "Swiss watch" of induction linacs.

14. Question: What tests of the proposed 11 ferrite-ring cell should be accomplished before the full procurement action is taken?

Answer: It seems to me that the upgraded cell should be tested for overvoltage reliability. As I recall, the original cells were tested well over 
their nominal operating voltage. The new cells should undergo a similar test.

15. Question: Could the Livermore FXR be used to answer any other questions?

Answer: It is possible that FXR might be used for some independent target interaction experiments. Indeed, the LLNL team might benefit from the experiments as well as LANL. However, it is not clear that the FXR beam spot is small enough to be very beneficial. In any case, I think the question should be examined. 


\subsection{Independent Consultant - Dr. William B. Herrmannsfeldt}

1. Question: Are the stated ITS performance milestones adequate to predict the performance of DARHT?

Answer: Yes, but the real significance is that the results of the tests have shown the hoped-for improvements. It was quite possible that the problems that were identified in FXR (alignment errors leading to corkscrew, etc.), were not the only causes of the observed spot size. If the ITS tests had not worked as well as they did, it would have meant that other problems still remained to be diagnosed and cured. The good results give great confidence that the real problems have been faced and the cures work.

2. Question: Is there enough information available to address ITS performance?

Answer: Yes, the information that has been collected is sufficient, except that in most areas some work is needed to complete the ongoing studies. These are noted below in responses to other questions.

3. Question: Is the performance of the injector (insulator) adequate?

Answer: No, a better solution is desired. See next question.

4. Question: Is the proposed (by LANL) tradeoff among injector parameters to maintain radiographic performance expectation considered acceptable?

Answer: Yes, it is acceptable, but it is not entirely desirable. The tradeoff uses most of the headroom that existed in the original conservative design. LANL should continue to work on this problem, as indeed they plan to do, including cooperating with the French/PSI work. Ultimately it may be desirable to go to an injector design that trades off some of the pulsed high voltage for some induction core voltage, similar to the SABRE and FXR approach.

5. Question: Are there any issues that should impact the FY'94 program procurement plan?

Answer: No. The team is ready to go and the design is ready to go.

6. Question: Has ITS milestone 5 been met or exceeded? 
Answer: Yes, this result is the main conclusion of this review.

7. Question: Has the tickler experiment been successfully completed and assessed?

Answer: Yes, up to the point where it has answered the critical questions. For future reference, some data needs to be obtained and analyzed, and reports prepared to finalize this study.

8. Question: Has beam/target interaction been adequately addressed?

Answer: No, while it is not apparent that any collective effects can spoil the performance of DARHT, this subject is suitable for some careful review.

9. Question: Are the technical risks associated with DARHT acceptable?

Answer: Yes, unconditionally.

10. Question: What is the probability that DARHT will meet its radiographic operating requirements?

Answer: Very high probably, although it should be anticipated that some time will be needed after first turn-on.

11. Question: Should the second axis differ significantly from the first?

Answer: If enhanced capabilities can be defined that address enhanced needs, then some significant improvements should be considered for inclusion in the second arm. See question 12.

12. Question: Are there any recommendations for further (1) DOE Technical Reviews? (2) R\&D Plans for radiography applications?

Answer: Yes, regarding radiography applications; the user community at both nuclear design laboratories should be involved, with the accelerator and radiography scientists, to determine the most useful options. Possibilities include multiple views at different angles, with multiple pulses, or gated single pulses, to get a radiographic motion picture of a test. Such a study should be made before it is necessary to freeze the design for the second arm of DARHT.

13. Question: Are there other recommendations? 
Answer: Considering the possibility that underground testing will not be restarted, there is also a possibility that a much more urgent need will arise for access to DARHT. The project is on a very slow, funding limited, schedule. Therefore LANL should develop a project plan for accelerating the schedule if the pace of funding is not constrained.

Operation of DARHT may be greatly improved by using an automated operating system of the type developed at FXR and further refined at ETA in Livermore. As LANL gets closer to operating DARHT (but before the ETA people have all left LLNL), the DARHT group should look into optimizing operating systems.

The reports from the DFAIC and HPAIC groups contain other recommendations that complement or extend the points made at this meeting and by these Independent Consultants. These recommendations should be reviewed from time to time.

14. Question: What tests of the proposed 11 ferrite-ring cell should be accomplished before the full procurement action is taken?

Answer: Pre-production prototypes should be built and tested, especially to confirm high-voltage operation.

15. Question: Could the Livermore FXR be used to answer any other questions?

Answer: Possibly, although the FXR schedule seems unlikely to permit much if any dedicated running. Unless and until FXR completes the upgrade, it is unlikely to show results that conclusively reflect on the expected performances of DARHT. 
4.5 Independent Consultant - Mr. James W. Lyle

1. Question: Are the stated ITS performance milestones adequate to predict the performance of DARHT?

Answer: Yes, the stated ITS performance milestones are adequate to predict the performance of DARHT.

2. Question: Is there enough information available to address ITS performance?

Answer: Yes, there is enough information available.

3. Question: Is the performance of the injector (insulator) adequate?

Answer: The nominal ITS beam characteristics as described in the DARHT Accelerator Development Plan have been achieved except for the beam energy. The Plan states a goal of $4 \mathrm{MeV}$ for this parameter while failures of the injector insulator have limited this energy to approximately 3.0 to 3.5 $\mathrm{MeV}$. The injector has logged shots in excess of 10,000 with only two failures to fire. Four failures of the insulator have occurred, three when using acrylic, and one when using epoxy. The failures do not seem to be caused by high voltage flashovers but are characterized by electron penetration into the material with the appearance of dendritic-like tunnels that are possibly lined with carbon and which grow until a shunt current path is formed. The epoxy insulator has been used on 7229 shots at voltages as high as $3.5 \mathrm{MV}$. It successfully performed an additional 86 shots at voltages between 3.5 and $3.75 \mathrm{MV}$. The failure occurred at $>3.5 \mathrm{MV}$. The designers are concerned about these dielectric failures and are implementing several possible solutions to the problem. In the meantime, given the present understanding of the failure mechanisms, choice of materials and design, a prudent hydrodynamic experimenter would operate the injector at a voltage somewhat diminished from the highest tested perhaps as much as 10 percent. The effect on the radiographic performance would certainly be a slightly diminished dose and possibly a slightly larger spot size. It is important to point out that on an explosive test a similar insulator failure would occur after the radiographic data had been successfully recorded. I feel confident that the insulator problem will be solved and that the injector will reach its goal of $4 \mathrm{MeV}$. The margin of safety above $4 \mathrm{MeV}$ has not yet been explored.

4. Question: Is the proposed (by LANL) tradeoff among injector parameters to maintain radiographic performance expectation considered acceptable? 
Answer: Yes, the various tradeoffs are acceptable.

5. Question: Are there any issues that should impact the FY'94 program procurement plan?

Answer: None that I know of.

6. Question: Has ITS milestone 5 been met or exceeded?

Answer: The ITS milestone 5 has been met except for the insulator failure that was discussed above.

7. Question: Has the tickler experiment been successfully completed and assessed?

Answer: The tickler experiment has been successfully completed and assessed and shows that the beam break up coupling impedances for the dominant modes at the nominal DARHT operating current are well within the safe range.

8. Question: Has beam/target interaction been adequately addressed?

Answer: Yes, but only for the present. New phenomena have been observed in the beam/target interaction that is not well understood. There is the exciting possibility that smaller radiographic spot sizes could be achieved and further experimentation should be undertaken but such work is not necessary now in order to realize the DARHT design goals.

9. Question: Are the technical risks associated with DARHT acceptable?

Answer: The technical risks associated with DARHT are acceptable.

10. Question: What is the probability that DARHT will meet its radiographic operating requirements?

Answer: The probability is high that DARHT will meet its radiographic operating requirements, but not necessarily when it is first turned on. The requirements of on-target electron current, energy, pulse width, and $x$-ray dose are highly likely to be met when the machine first becomes operational. The spot size of 1.2-mm-diameter $4 \mathrm{rms}$ time-averaged over 60 ns is the more difficult goal to realize, but it is possible given our present understanding of the physics, the design of the machine, and the demonstrated performance of the Integrated Test Stand (ITS). The 
performance history of electron accelerators for flash radiography shows that the machines were considerably improved in a few years from the original start-up. Such improvement is expected to occur for DARHT as well. There are tradeoffs available to optimize various radiographic tasks. For example, the spot size can be made smaller through the use of collimation at a sacrifice of some dose. Dose can be increased with higher electron energy which might require additional accelerating cavities for which the designers have already provided.

11. Question: Should the second axis differ significantly from the first?

Answer: The answer depends upon how many years have passed before the decision is made to build a second axis. If not much time has elapsed, then the second axis should not differ significantly from the first unless a different design offered a clear radiographic improvement. Arguments in favor of the same technology involve cost, operating experience, spare parts inventory, and the incorporation of improvements. Flash x-ray technology will improve with time. If many years pass before a decision is made to build a second axis then the technology used on the first axis may well be obsolete.

12. Question: Are there any recommendations for further (1) DOE Technical Reviews? (2) R\&D Plans for radiography applications?

Answer: I do not think further DOE technical reviews are needed for DARHT. It may be helpful if the technical consultants were made aware of progress on the injector insulator and any further studies of the beam/target interaction. Perhaps they could receive data and reports by mail.

The beam/target interaction studies should be continued. There may be some machine calculations that could be made to better understand the observed phenomena.

13. Question: Are there other recommendations?

Answer: The DARHT designers have provided spaces for the installation of various optical diagnostic equipment including seven high speed rotating mirror cameras, laser shot illumination, image intensifier photography, and interferometric measurement of free surface velocity. All of this optical equipment has been under development at LANL and LLNL for some time. While LLNL personnel have consulted with the designers of DARHT and have participated in the conceptual designs, much more could be accomplished toward a "user" facility if cooperation between the laboratories were to continue. For Example: 
- Cost saving provisions could be made for the future installation of hydraulic camera hoists in the optics room floor if, during Title I and II design, attention were given to the placement of the concrete forms and the steel reinforcing bars.

- Sufficient ceiling height should be carefully considered in the rotating mirror camera room so that a broad range of image formatting could be accomplished.

- To avoid damage and to reduce labor, it is better to store off-hoist cameras in the same room in which they are used than to ship them to another storage facility. Sufficient floor space should be provided for this storage.

- The cooperative specification of utilities and their location in the various optical diagnostic spaces could be beneficial.

- In addition to the radiographic core-punching capability, the DARHT multi-diagnostic "user" facility could be used for a great variety of other kinds of explosively driven experiments. The maximum explosive weight placed at the 2-axis intersection point for DARHT has been set at $70 \mathrm{~kg}$. This quantity appears to me to be quite conservative. Proposals for experiments will likely be made that contain more than 70 $\mathrm{kg}$. Because of their possibly large dimensions, some of the proposed experiments and auxiliary firing table equipment might not fit very well at the intersection point. The designers of DARHT should consider other shot location points to determine if the buildings could be made to sustain increased blast loading on their sides.

14. Question: What tests of the proposed 11 ferrite-ring cell should be accomplished before the full procurement action is taken?

Answer: I defer to Andy Faltens for a detailed answer to this question.

15. Question: Could the Livermore FXR be used to answer any other questions?

Answer: FXR could be used to answer questions that may be important both for the design of DARHT and for improvements of the FXR. For example, the interactions of the tightly focused electron beam and the bremsstrahlung target could be explored to improve our understanding of some very complex electronic and hydrodynamic phenomena that has recently been observed on the ITS. The FXR could be used in the postaccelerator drift region to develop a more nearly achromatic focusing system. A tickler-like experiment could be done on FXR in which microwave energy could be introduced while evidence of propagation of beam break-up modes is examined. 


\subsection{Independent Consultant - Dr. Craig L. Olson}

1. Question: Are the stated ITS performance milestones adequate to predict the performance of DARHT?

Answer: The ITS performance milestones appear to be adequate to predict the performance of DARHT. Corkscrew has been alleviated by minimizing alignment errors. Beam breakup has been shown to be negligible based on present ITS tickler experiment results. Current beam/target interaction results suggest some type of filamentation may be occurring; continuing study should ensure that it does not affect DARHT performance.

2. Question: Is there enough information available to address ITS performance?

Answer: Yes. ITS performance has been addressed well.

3. Question: Is the performance of the injector (insulator) adequate?

Answer: The insulator now appears to be adequate at the reduced voltage of 3-3.5 MV (down from the design goal of $4 \mathrm{MV}$ ). Work on the insulator problem should continue in conjunction with tradeoffs. LANL may benefit from talking to people at SNL with expertise in this area.

4. Question: Is the proposed (by LANL) tradeoff among injector parameters to maintain radiographic performance expectation considered acceptable?

Answer: The proposed tradeoffs were only discussed in general terms. At the review, it was requested that LANL prepare a consistent set of end-toend parameters for each tradeoff case; to my knowledge, this has not yet been done, and it should still be done.

5. Question: Are there any issues that should impact the FY'94 program procurement plan?

Answer: Yes. The plan includes procurement of one complete accelerator, and procurement of a perpendicular footprint (concrete base plus utilities) for the second accelerator. Procurement for one complete accelerator should proceed without delay. However, procurement of the perpendicular footprint should not occur until LANL has analyzed other footprint possibilities such as using two parallel accelerators with final $45^{\circ}$ bends. This would permit perpendicular views, but also the possibility of timesequenced almost parallel views. The beam quality will be high enough to permit the use of bending magnets. Other advantages of magnetic bends are (1) avoidance of debris sent backwards into the accelerator, and (2) removal of the low energy rise and fall of the beam pulse. These advantages could hold also for the perpendicular accelerator case, but 
sufficient space for beam manipulation would need to be added to the baseline design. The parallel accelerator case seems simpler and it should probably have a cost advantage as well. These options should be analyzed before proceeding with the proposed perpendicular footprint.

6. Question: Has ITS milestone 5 been met or exceeded?

Answer: Yes. A dose greater than $18 \mathrm{Rad}$ and a spot size smaller than 4.7 $\mathrm{mm}$ have been achieved.

7. Question: Has the tickler experiment been successfully completed and assessed?

Answer: Yes. An upper bound has been established for BBU (Beam Break Up) growth that shows that BBU will not be a problem for the full accelerator. The theoretical analysis of George Caporaso and Tom Hughes, and the experimental work of Dave Moir, Paul Allison, and Mike Burns are to be commended. Work should continue to improve the agreement between code results and experiments. Other parameters should now be varied, such as the current, for a thorough understanding of BBU.

8. Question: Has beam/target interaction been adequately addressed?

Answer: The beam/target interaction is just beginning to be studied on ITS. There is some evidence of filamentation, and this should be studied further to ensure that it will not affect DARHT performance.

9. Question: Are the technical risks associated with DARHT acceptable?

Answer: Yes. The technical risks appear to be acceptable, especially since there will be continuing analysis of $\mathrm{BBU}$, the insulator issue, and the beam/target interaction.

10. Question: What is the probability that DARHT will meet its radiographic operating requirements?

Answer: The probability is high that DARHT will meet its radiographic operating requirements after an initial shakedown period.

11. Question: Should the second axis differ significantly from the first?

Answer: The second axis may differ from the first axis because of experience gained from the first axis, development of alternate technologies, the possibility of using bending magnets, etc.. The decision to build the second axis will benefit from this increased knowledge.

12. Question: Are there any recommendations for further (1) DOE Technical Reviews? (2) R\&D Plans for radiography applications? 
Answer: DOE technical reviews may be appropriate every 2-3 years.

13. Question: Are there other recommendations?

Answer: The LANL/LLNL/MRC (Mission Research Corporation) team did an excellent job on the ITS. The collaboration with George Caporaso is especially to be commended, and the working interaction between LANL and LLNL should continue.

14. Question: What tests of the proposed 11 ferrite-ring cell should be accomplished before the full procurement action is taken?

Answer: The expected pulselength operation should be verified and the high voltage holdoff should be tested.

15. Question: Could the Livermore FXR be used to answer any other questions?

Answer: FXR may be useful for studying the beam/target interaction behavior observed on ITS. 


\subsection{PROFESSIONAL PROFILES OF INDEPENDENT CONSULTANTS, CHAIRMAN, AND EXECUTIVE SECRETARY}




\author{
Dr. Richard K. Cooper \\ Los Alamos National Laboratory
}

Education:

1964

Ph.D. in Theoretical Nuclear Physics

University of Arizona

Tucson, AZ

1959

1958

MSEE

BSEE

California Institute of Technology

Pasadena, CA

Experience:

1990-Pres

Staff Member

Accelerator Theory and FEL Technology Group, AT-7

Los Alamos National Laboratory

Los Alamos, NM and

Visiting Professor

Physics Department

University of California at Los Angeles

Los Angeles, CA

1982-1990

Group Leader

Accelerator Theory and simulation Group, AT- 6

Los Alamos National Laboratory

Los Alamos, NM

1976-1982

Staff Member

(Deputy Group Leader 1976-1979)

Proton Storage Ring Group

Los Alamos National Laboratory

Los Alamos, NM

1965-1976

Physics Faculty

California State University at Harvard

Hayward, CA

and

Consultant

Accelerator Technology

Los Alamos National Laboratory

Los Alamos, NM 
Activities/Areas of Interest:

- $\quad$ Free electron laser theory.

- $\quad$ Studying the effect of rf structure and other beam structures on cumulative beam breakup.

- $\quad$ Theory of induction linacs.

- $\quad$ Developing three-dimensional codes for accelerator applications.

- $\quad$ Design of proton storage ring.

- $\quad$ Design of fast-kicker magnet and its pulse-forming network.

- Teaching of graduate level physics courses. 
Mr. Andy Faltens

Lawrence Berkeley Laboratory

Education:

1964

MSEE

University of California

Berkeley, CA

1962

BSEE

MIT

Cambridge, MA

Experience:

1964 - Pres

Senior Scientist

Lawrence Berkeley Laboratory

Berkeley, CA

Activities/Areas of Interest:

- Induction linacs.

- $\quad$ Primary innovator of the ferrite core, Blumlein fed, spark gap

switched short pulse high current electron induction linacs.

- Consulted on design of the ETA, ATA and FXR induction linacs.

- Designed many of the nanosecond response capacitive dividers, loops and wall current monitors.

- $\quad$ Experience on transverse and longitudinal beam instabilities.

- Linear and circular machine impedances.

- Currently designing heavy ion inductor linacs for inertial confinement fusion. 


\section{Dr. Terry F. Godlove}

FM Technologies, Inc.

Education:

1955

Ph.D. in Physics

Yale University

New Haven, CT

Experience:

1987 - Pres

Senior Scientist

FM Technologies

Fairfax, VA

1986-1987

Senior Scientist

La Jolla Institute

San Diego, CA

1977-1986

Manager

Heavy Ion Fusion Accelerator Research \&

Light Ion Beam Inertial Confinement Fusion Program

Department of Energy

Georgetown, MD

1975-1977

Branch Head

Electron Beam Applications/Plasma Physics Division Naval Research Laboratory

Washington, DC

1960-1975

Branch Head

Linac/Nucleonics Division

Naval Research Laboratory

Washington, DC

$1955-1960$

Scientist

Nuclear Interactions Branch/Nucleonics Division

Naval Research Laboratory

Washington, DC 


\section{Dr. Terry F. Godlove \\ $-2-$}

Activities/Areas of Interest:

- Design, development and construction of experimental air-core synchrotron.

- Design, construction and operations of the NRL Linac.

- $\quad$ Basic and applied research programs using NRL Linac.

- $\quad$ Advanced microwave and millimeter-wave research, including directed energy microwave.

- $\quad$ Generators and advanced accelerator research.

- Heavy ion fusion accelerator research. 


\author{
Dr. William B. Herrmannsfeldt \\ Stanford Linear Accelerator Center
}

Education:

1958

Ph.D. in Physics

University of Illinois

Urbana, IL

Experience:

1962 - Pres

Staff Member

Stanford Linear Accelerator Center

Stanford, CA

1958-1962

Staff Member

Los Alamos Scientific Laboratory

Los Alamos, NM

Activities/Areas of Interest:

- $\quad$ Electron gun design.

- $\quad$ RF bunching calculations for Linac injector.

- Beam transport systems.

- $\quad$ Numerical modeling of accelerator systems.

- $\quad$ Numerical modeling of high power RF systems.

- Heavy ion fusion accelerator research and development.

- $\quad$ High brightness ion injection systems.

- $\quad$ High intensity, short pulse, high energy electron beams.

- $\quad$ High Power RF systems.

- $\quad$ High intensity heavy ion injectors.

- $\quad$ High brightness injectors for free electron lasers.

- Research and development for electron/positron linear colliders. 


\author{
Mr. James W. Lyle \\ Lawrence Livermore National Laboratory
}

Education:

1953

B.S. Engineering Physics

University of Michigan

Ann Arbor, MI

Experience:

1964-Pres

Physicist

B-Division

Lawrence Livermore National Laboratory

Livermore, CA

1957-1964

Engineer

Linde Division, Union Carbide Corporation

Speedway Research Laboratory

Speedway, IN

1955-1957

Lt. USN

Assistant Professor of Naval Science

Vanderbilt University

Nashville, TN

1953-1955

Ens. USN

Gunnery Officer USS Foss (DE-59)

Activities/Areas of Interest:

- Methods of flame spraying refractory hard metal coatings.

- Growth of single crystals.

- $\quad$ Electric welding.

- Design and use of electron accelerators for flash radiography.

- Improving an L-band traveling wave electron accelerator.

- Building and using smooth bore guns for equation-of-state measurements of plutonium, and other metals and alloys. 
Mr. James W. Lyle

$-2-$

Applied hydrodynamics.

- $\quad$ Building and fielding 13 devices at the Nevada Test Site.

- $\quad$ Initiating the FXR at Site 300.

- $\quad$ Transferring the core-punch technology from Great Britain to Livermore.

- $\quad$ Initiating the Fabry-Perot velocimeter at Livermore.

- Intelligence activities regarding the nuclear weapons program of the Soviet Union.

- Writing Safety Analysis Reports. 
Dr. Craig L. Olson

Sandia National Laboratories

Education:

1970

Ph.D. in Physics

UCLA

Los Angeles, CA

Experience:

1992-Pres

Manager

Beam, Plasma and Electromagnetic Theory Department Sandia National Laboratories

Albuquerque, NM

1991-1992

Supervisor

Plasma Physics Theory Division

Sandia National Laboratories

Albuquerque, NM

1970-1991

Staff Member

Plasma Physics Theory Division

Sandia National Laboratories

Albuquerque, NM

1964-1970

Summer Staff

RAND Corporation

Los Angeles, CA

Activities/Areas of Interest:

- $\quad$ Intense electron beam transport.

- Intense ion beam transport.

- $\quad$ Beam/plasma instabilities.

- $\quad$ Sources of intense ion beam divergence.

- $\quad$ Emittance growth in intense beams.

- $\quad$ Focusing theories for intense electron beams.

- Propagation and focusing of intense ion beams.

- Collective ion acceleration.

- $\quad$ Ion beam drivers for Inertial Confinement Fusion. 
Mr. Jim Kapsales

U.S. Department of Energy

Chairman

Education:

1974

B.S. in Physics

Syracuse University

Experience:

1991-Pres

Physicist/Weapons Physics Program Manager DOE/Defense Programs

Germantown, MD

1987-1991

Nuclear Engineer/Physicist

DOE/Office of Foreign Intelligence

Washington, DC

1982-1987

Engineer/Department Head

U.S. Naval Intelligence Support Center

Radiation Division

Suitland, MD

1980-1982

Technical Associate/Physicist

E.R. John Associates, Inc. and Nuclear Audit and Test Company, Inc.

Reston, VA

$1976-1980$

Staff Officer/Physics Instructor

Physics Division Track Coordinator

U.S. Naval Nuclear Power School

NTC Orlando, FL

1983-Pres

Commander, U.S. Naval Reserve

Theater Nuclear Warfare Program Office

Crystal City, VA

Activities/Areas of Interest

Chairman, 1993 DARHT Accelerator Review 
Mr. Jim Kapsales

$-2-$

- Defense Programs Technical Advisor to the Source Evaluation Board for Sandia National Laboratories M\&O Contract Procurement, 1992-1993.

- $\quad$ Coordinator, Hydrotest Program Assessment Independent Consultants.

- $\quad$ Coordinator, DARHT Feasibility Assessment Independent Consultants.

- $\quad$ Nuclear Weapons Research and Development Management.

- $\quad$ Chairman, User Panel for Intelligence, DOE/Office of Foreign Intelligence, Weapons Intelligence Division.

- Joint Atomic Energy Intelligence Committee Working Group on Nuclear Proliferation/Weapons/Logistics.

- Measurement and Signals Intelligence Committee Working Group on Nuclear Intelligence.

- Weapons and Space Science Intelligence Committee Working Group on Aerodynamic Missile Systems.

- $\quad$ Naval Tactical Nuclear Weapons Program Management.

- Nuclear Weapons Training/Intelligence.

- $\quad$ Arms Control and Verification Intelligence.

- $\quad$ Terminal Disposal of Spent Unreprocessed LWR Fuel.

- Commercial Nuclear Fuel Fabrication Quality Assurance.

- $\quad$ Physics Instruction and Education. 


\section{Dr. Henry (Arch) Thiessen \\ Los Alamos National Laboratory \\ Executive Secretary}

Education:

1967

Ph.D. in Physics

California Institute of Technology

Pasadena, CA

1962

M.S. in Physics

California Institute of Technology

Pasadena, CA

1961

B.S. in Physics

California Institute of Technology

Pasadena, CA

Experience:

1981-Pres Group Leader

Advanced Accelerator Concepts, LAMPF

Los Alamos National Laboratory

Los Alamos, NM

1971-1981 Group Leader

Spectrometer Group, LAMPF

Los Alamos National Laboratory

Los Alamos, NM

1966-1971 Staff Member

Los Alamos National Laboratory

Los Alamos, NM

Activities/Areas of Interest

- $\quad$ High power upgrades to LAMPF.

- Circular accelerator design.

- Circular accelerator beam dynamics.

- Instabilities of proton storage ring.

- Collimation and beam losses in circular accelerators. 


\section{Dr. Henry (Arch) Thiessen}

- $\quad$ Superconducting RF cavities.

- Design of superconducting linac for protons.

- KAON factory.

- $\quad$ Advanced spallation neutron source design.

- Hypernuclear physics.

- $\quad$ Pion-nucleus physics.

- $\quad$ High resolution beam lines and spectrometers.

- $\quad$ Targets and shielding for high current proton linacs. 


\section{APPENDIX A}

\section{LIST OF ACRONYMS}

\begin{tabular}{ll} 
ADP & Accelerator Development Plan \\
ATA & Advanced Test Accelerator \\
BBU & Beam Break Up \\
DARHT & Dual Axis Radiographic Hydrotest \\
DFAIC & DARHT Feasibility Assessment Independent Consultants \\
DOE & Department of Energy \\
DP & Defense Programs \\
ES\&H & Environment, Safety and Health \\
ERA & Electron Ring Accelerator \\
ETA & Experimental Test Accelerator \\
FOM & Figure of Merit \\
FWHM & Full Width at Half Maximum \\
FXR & Flash X-Ray machine \\
FY & Fiscal Year \\
HEAF & High Explosives Application Facility \\
HFS & Hydrotest Firing Site \\
HPAIC & Hydrotest Program Assessment Independent Consultants \\
ITS & Integrated Test Stand \\
LANL & Los Alamos National Laboratory \\
LBL & Lawrence Berkeley Laboratory \\
LIA & Linear Induction Accelerator \\
LLNL & Lawrence Livermore National Laboratory \\
\hline
\end{tabular}




$\begin{array}{ll}\text { MV } & \text { Megavolt } \\ \text { MeV } & \text { Million Electron Volt } \\ \text { mm } & \text { millimeter } \\ \text { MRC } & \text { Mission Research Corporation } \\ \text { NRL } & \text { Naval Research Laboratory } \\ \text { ns } & \text { nanoseconds } \\ \text { PHERMEX } & \text { Pulsed High Energy Radiographic Machine Emitting X-Rays } \\ \text { R\&D } & \text { Research and Development } \\ \text { RSL } & \text { Radiographic Support Laboratory } \\ \text { rms } & \text { root mean square } \\ \text { SABRE } & \text { Sandia Accelerator for Beam Research Experiments } \\ \text { SNL } & \text { Sandia National Laboratories } \\ \text { TEC } & \text { Total Estimated Cost } \\ \text { WBS } & \text { Work Breakdown Structure } \\ \text { WWII } & \text { World War II }\end{array}$




\section{APPENDIX B}

\section{Charge from DOE}

The following consultants, Chaired by Jim Kapsales of DP-242, will be asked to provide independent technical input to DOE regarding the DARHT facility:

Dr. Terry F. Godlove, FM Technologies

Dr. William B. Herrmannsfeldt, SLAC

Mr. James W. Lyle, LLNL Associate (retired)

Dr. Craig L. Olson, SNL

Dr. Richard K. Cooper, LANL/AT-7

Mr. Andy Faltens, LBL

Dr. Phillip Sprangle, NRL (tentative)

If requested by the Chairman, an executive secretary and ex-officio members from SNL, LLNL, LANL, or elsewhere may be added. Jim Kapsales will serve as Chairman for the initial review period. After initial review, the consultants will meet in executive session to decide if further review is needed; if so, they will propose a chairman and any necessary modifications to the charter and submit those recommendations for DOE approval.

The following consultants may also be asked to contribute technical input on an as needed basis:

Mr. Peter W. J. Moore, Atomic Weapons Establishment (Aldermaston)

Dr. Ray Pollock, Consultant

Dr. Juan J. Ramirez, SNL

\section{Charter}

Evaluate the DARHT Facility design and the performance of the Integrated Test Stand (ITS) and the first axis of DARHT. Provide an independent assessment of the probability that DARHT will meet its radiographic hydrotest performance and operating requirements. Provide recommendations on and assessment of improvements which might enhance hydrodynamics capability. Specifically:

1. Has the ITS met or exceeded its stated performance milestones (including the Tickler experiment)?

2. Do the stated ITS/DARHT performance milestones remain adequate for assessing ITS and DARHT?

3. Is the performance of the injector insulator reliable?

4. Are there any recommended modifications to the DARHT Project Plan?

5. Are there any other recommendations? 
Evaluations should be completed by summer 1993. The review is tentatively scheduled for June 15-16, 1993, at LANL. Each consultant will provide an individual written assessment and recommendations. Consensus is not required or expected. 


\section{Distribution List}

FM Technologies 9713 Manteo Court

Ft. Washington, MD 20744

Attn: (1) Dr. Terry F. Godlove

\section{SLAC}

PO Box 4349, MS-26

Stanford, CA 94309

Attn: (1) Dr. William Herrmannsfeldt

Commanding Officer

Naval Research Laboratory

4555 Overlook Avenue, SW

Washington, DC 20375

Attn: (1) Dr. David Nagel (4600)

(1) Dr. Phillip Sprangle (4790)

Pacific-Sierra Research Corp. 1401 Wilson Blvd., Suite 1100

Arlington, VA 22209

Attn: (1) Mr. Frank J. Thomas

PSR Services Inc.

1401 Wilson Boulevard

Arlington, VA 22209

Attn: (1) Mr. John J. Kelley

Science Applications International

Corp.

PO Box 244

Hanover, NH 03755

Attn: (1) Mr. David K. Hall

2509 Boulder Rd.

Atladena, CA 91125

Attn: (1) Dr. Steven E. Koonin

6304 Cove Road

Bethesda, MD 20817

Attn: (1) Dr. Ray Pollock

Kaman Sciences Corporation Washington Operations Division 2560 Huntington Ave.

Alexandria, VA 22303

Attn: (1) Dr. Richard L. Wagner, Jr.

AWE

Head of Warhead Hydrodynamics

READING

Berkshire RG7 4PR

United Kingdom

Attn: (1) Mr. Peter W.J. Moore
Lawrence Berkeley Laboratory

One Cyclotron Road

Berkeley, CA 94720

Attn: (1) Mr. Andy Faltens

Los Alamos National Laboratory PO Box 1663

Los Alamos, NM 87545

Attn: (1) Dr. Harry C. Hoyt

(1) Dr. John Immele

(1) Dr. Dennis Erickson

(1) Dr. Larry Madsen

(1) Dr. Don Wolkerstorfer

(1) Dr. Richard Krajcik

(1) Dr. Timothy Neal

(1) Dr. Jim Porter

(1) Mr. Ed Jolly

(1) Mr. Mike Burns

(1) Dr. David Moir

(1) Dr. Paul Allison

(1) Mr. Randy Carlson

(1) Dr. James Downing

(1) Dr. Richard Cooper

(3) Dr. Henry Thiessen

(3) Mr. Robert Stapleton

Lawrence Livermore National

Laboratory

PO Box 808

Livermore, CA 94550

Attn: (1) Dr. Seymour Sack

(2) Dr. George Miller

(1) Dr. Mike Anastasio

(1) Dr. Lloyd Multhauf

(1) Mr. C. F. Joe Baker

(1) Dr. George Caporaso

(1) Dr. David R. Goosman

(2) Mr. James W. Lyle

Department of Energy 19901 Germantown Rd.

Germantown, MD 20585

Attn: (2) DP-20

(1) DP-20.1

(1) DP-20.5

(1) DP-21

(1) DP-23

(1) DP-24

(1) DP-242 Dr. Greg D'Alessio

(16) DP-242 Mr. Jim Kapsales

(1) DP-242 Mr. Paul Vogel

(1) DP-242 Dr. John Sarracino

(1) DP-242 Dr. Laura Gilliom 
(1) DP-25

(1) DP-252 Mr. Irv Williams

(2) DP-252 Mr. Bob Gunderson

(1) DP-532 Ms. Kate Foley

(1) DP-662 Mr. Larsen L. Furr

(2) DP-662 Mr. Robert Hamby

Department of Energy

Forrestal Building

1000 Independence Avenue, SW

Washington, D.C. 20585

Attn: (1) DP-1 Dr. Everette Beckner

(1) DP-4 Dr. Warren P. Chernock

(1) DP-4.2 Dr. Maury Katz

(1) DP-4.2 Mr. J. Ken Schafer

(1) DP-40

(1) DP-60

DOE/AL/PMD

PO Box 5400

Albuquerque, NM 87185

Attn: (1) Mr. Lee Le-Doux

DOE/LAAO/PMB

528 35th Street

Los Alamos, NM 87544

Attn: (1) Dr. J. L. Bellows

DOE/SAN/WDD

PO Box 5800

Albuquerque, NM 87185

Attn: (1) Mr. Phil Duarte

DOE/AL/KAO

Albuquerque Field Office

Albuquerque, NM 87185

Attn: (1) Mr. Herbert C. Bohannon, Jr.

Sandia National Laboratories

PO Box 5800

Albuquerque, NM 87185

Attn: (1) 1000 Dr. Paul Fleury

(1) 1202 Dr. Donald Cook

(1) 1203 Dr. Kenneth Prestwich

(1) 1204 Dr. Juan Ramirez

(1) 1231 Dr. Mike Mazarakis

(1) 1241 Dr. Craig Olson

(1) 4202 Dr. David Larson

(1) 4700 Dr. Pace VanDevender

(1) 5000 Dr. R. L. Hagengruber

(1) 5601 Dr. James Gerardo

(1) 5602 Dr. Dennis Hayes 